\title{
Methods of helping patients with behaviour change
}

\author{
Stephen Rollnick, Paul Kinnersley, Nigel Stott
}

Helping patients to change behaviour concerned with eating, drinking, smoking, exercise, or taking medication is a common task in medical consultations. In both hospital and primary care the care of chronically ill people often entails encouraging them to change behaviour. With the emphasis now placed on health promotion in primary care this activity has been given high priority. ${ }^{12}$ Yet health care practitioners are given little or no training in how to promote behaviour change. We examine the limitations of using the approach of giving advice and identify new concepts and methods which offer the promise of improving the quality and effectiveness of consultations about behaviour change.

\section{Giving advice and its limitations}

Giving advice seems to form the basis of most discussions on behaviour change. This is evident in both the study of consulting behaviour ${ }^{3}$ and reports of outcome studies of secondary prevention among smokers ${ }^{4}$ and drinkers. ${ }^{5}$ The logic of this approach seems to be that people lack information which, if received from a respected source, is sufficiently compelling to produce change. This method can be used in a more or less authoritarian style, but it relies on an essentially paternalistic doctor-patient relationship in which the practitioner tries to persuade the patient about the wisdom of considering a change of lifestyle.

The main limitation of giving advice about lifestyle is that the evidence of its effectiveness is not very convincing. On the one hand, it is clear that brief interventions for behaviours like smoking and heavy drinking has some benefit, in the sense that recipients of brief advice fare better than their counterparts in control conditions. ${ }^{47}$ On the other hand, it is also apparent that the size of the effects of treatment in these studies is fairly small, with success rates of $5-10 \%$ not uncommon. Thus, while some patients seem to respond to advice, most do not. Further evidence from consumer studies suggests that patients are not uniformly committed to receiving advice, especially if it is unsolicited and not clearly related to the presenting problem. ${ }^{8}$

Another limitation of giving advice is that it can have a negative effect on the two participants in the consultation. It is a common experience to find unsolicited advice being met by resistance from the patient. This often takes the form of a dialogue characterised by a "yes, but..." response from the patient. Thus discussion of behaviour change clearly risks a clash of agendas between patient and practitioner. ${ }^{3}$ In their efforts to change behaviour practitioners are likely to be general in their outlook, placing emphasis on the benefits of change while undervaluing the personal costs. Patients will look very closely at the personal implications of change and are likely to be concerned about immediate costs while discounting future benefits.

In summary, giving advice is limited in effectiveness and can readily descend into non-constructive disagreement. It is possible to argue, as several writers have done, ${ }^{45}$ that despite the fairly weak effectiveness of this kind of brief intervention the benefits to public health of widespread application would be consider-

able if performed in most consultations. This remains an open question. If many of the consultations end unsatisfactorily widespread uptake may not occur. Moreover, it can also be argued that the main rationale for discussing behaviour change is for the benefit of the individual patient. However this issue is resolved, it seems appropriate to consider ways of improving the effectiveness and quality of methods for encouraging changes in behaviour.

\section{Some developments in addiction research}

Several developments have taken place in research on addictions over the past 10 years which have a direct bearing on the understanding of negotiating changes in behaviour. Specialists in addiction have studied not only smoking and drinking behaviour and the treatment of them, but also other behaviours such as eating and taking exercise, on the grounds that these can also develop into habits which are difficult to break.

\section{AMBIVALENCE}

One potentially useful concept is that of "ambivalence," which in this context does not mean simply a reluctance to do something but the experience of heightened psychological conflict about choosing between two courses of action. In the case of smokers, for example, the conflict is between smoking and abstaining; with overeaters it is between their usual eating habits and the prospect of changing their diet. Ambivalence about behaviour change is difficult to resolve because each side of the conflict has benefits and costs associated with it.?

The kind of "Yes, but..." response to giving advice described above has been reviewed in some detail in the treatment of addiction. ${ }^{111}$ The hypothesis has arisen that when someone is feeling ambivalent about behaviour change an overtly persuasive effort from the practitioner is likely to lead to resistance from the patient. In other words, if the practitioner argues for the benefits of change or the costs of continuing with harmful behaviour patients will naturally present the other side of their conflict, usually in the form of a "yes but..." response. Some support for this hypothesis has emerged from the analysis of tape recordings of counselling interviews with problem drinkers. ${ }^{12}$ It seems that confrontational interventions from the practitioner-for example, "Your drinking seems to be causing you some quite serious medical problems, don't you think?"-were associated with resistance from the patient. The number of confrontational statements from the practitioner correlated with poor outcome some 12 months later. ${ }^{12}$ The main implication of this work is that practitioners' consulting behaviour can affect the degree of resistance which emerges, and subsequent outcome. Stated positively, a patient's motivation to change can be enhanced by using a negotiation method in which the patient, not the practitioner, articulates the benefits and costs involved.

\section{READINESS TO CHANGE}

Another concept from research on addiction, arguably one of the most influential to emerge in recent years, ${ }^{13} 1$ is that of "readiness to change." This is based on the "stages of change" model, which describes the

Maelfa, Llanedeyrn, Cardiff

$B M F$ 1993;307:188-90 


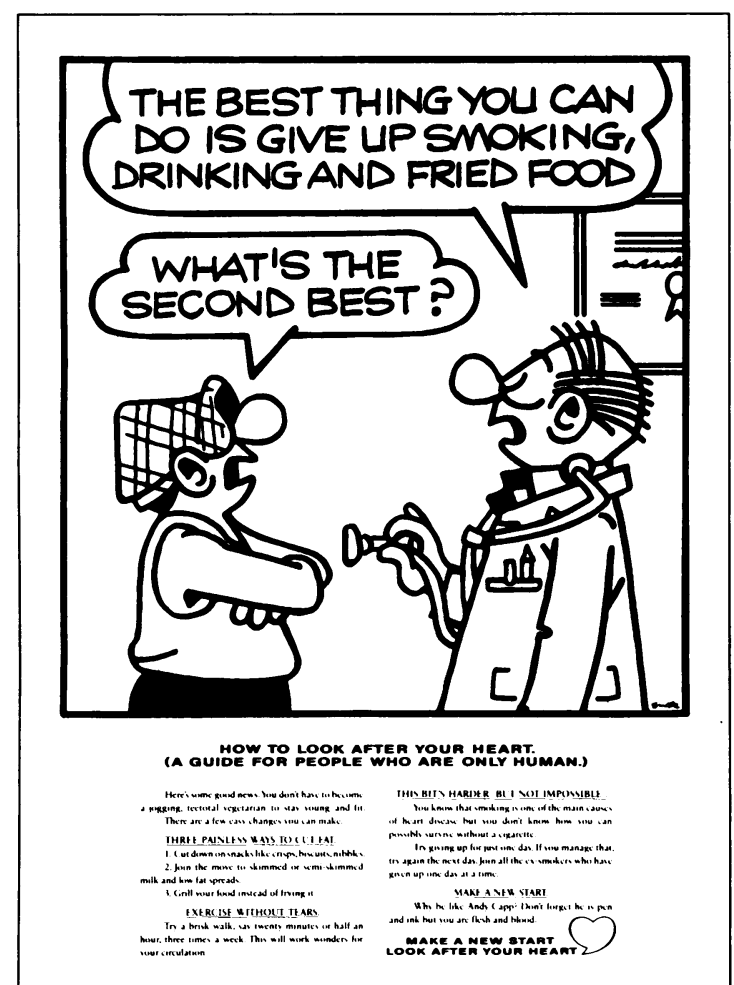

The concept of "readiness to change" can help a doctor tailor hi messages to people at different stages of willingness to change their behaviour

variety of motivational states encountered among patients, ranging from those who are not interested in considering change (called "precontemplators") through those uncertain about the prospect ("contemplators") to those who are ready to change ("preparation stage"). ${ }^{15}$ Two further stages refer to those who have already embarked on change (the "action" and "maintenance" stages). One striking observation has been that only a third (at most) of smokers and heavy drinkers are actually ready to change, the rest being in the precontemplation or contemplation stage. ${ }^{16}{ }^{17}$ Examination of the behaviour of smokers, for example, shows that they do move through these stages in an orderly manner, seldom leaping over one or more stages. ${ }^{14}$ A variety of methods for assessing this construct have also been developed..$^{14} 1618$

The concept of readiness to change is relevant to the negotiation of behaviour change in medical consultations for several reasons. Firstly, it might help to explain why simple advice giving is limited in effectiveness. If patients are not ready for action-for example, they are in the contemplation stage - they will resist advice because the practitioner is jumping ahead and assuming that they are or should be ready to change. Secondly, the concept of readiness to change highlights the fact that the decision to change behaviour is a process not a discrete event. This process entails frequent movements towards change and back again towards indulging in the behaviour. Therefore, concrete behaviour change is not necessarily the only worthwhile goal to pursue in a consultation. Helping someone to think about change could lead to success at a later point in time. Thirdly, the possibility has emerged that interventions can be tailored to suit the degree of readiness to change of the individual patient. This should ensure greater parity between the agendas of practitioner and patient, thereby minimising the emergence of resistance and improving the effectiveness of intervention.

The concept of readiness to change can be linked to that of ambivalence in a clinically useful way. As someone moves from the contemplation stage to the preparation stage-that is, coming towards a decision to change behaviour - the ambivalence conflict will be experienced in its most heightened form. As so many patients are likely to be in the contemplation stage during the consultation, progress will depend on helping the patient to resolve this ambivalence. This is one of the major challenges facing those concerned with the development of new methods.

\section{Development of new negotiating methods}

One obvious way of improving the approach to consultations concerning changes in behaviour is to tailor intervention to the readiness to change of the patients. This has been done by dividing patients into groups (for example, not ready, unsure, and ready) and training practitioners to respond accordingly. Brief intervention packages have been designed along these lines for use among heavy drinkers ${ }^{19}$ and smokers ${ }^{20}$ in general practice. Guidelines written for primary health care workers on alcohol ${ }^{21}$ and general health promotion ${ }^{2}$ have also taken up this approach. In general, the intervention becomes more intensive with increasing readiness to change. Thus the precontemplator will simply be given information; the contemplator will be given the opportunity to weigh up the pros and cons of the behaviour; while those ready for change will be engaged in a discussion about how to proceed with changing their behaviour.

Even such an apparently simple system is not free of problems. Practitioners have to get used to a quite different way of working, and, crucially, as most patients are in the contemplation stage, in which ambivalence is a central problem, they have to learn how to deal with ambivalence in a constructive way. To date only one controlled trial of a package based on dividing patients into groups has been performed, with mixed results. ${ }^{22}$ Other priorities for research on this topic should include the methods used to categorise patients into groups, the process of acquiring new skills during training, and the expansion of the framework to include not just one behaviour but any behaviour chosen by practitioner and patient.

An alternative approach is not to divide patients into groups, but to train practitioners to respond in a more flexible and continuous way to their judgments about the patient's readiness to change. This forms the basis of a method developed within research on addiction called motivational interviewing, ${ }^{11}$ in which counselling skills such as reflective listening guide the negotiation of behaviour change. This method has been adapted for use by staff in hospital working with heavy drinkers. ${ }^{23}$ It is based on the use of brief strategies which are matched to the perceived readiness to change of the patient in a consultation which is generally longer than its equivalent in primary care. Work is now under way on refining this latter method for use in a briefer consultation, which can be focused on any behaviour.

Clearly, the pursuit of new methods for negotiating behaviour change is a subject still in the early stages of its development. Indeed, the term "behaviour change" itself is seldom discussed outside specialist psychological publications, despite the fact that health care practitioners spend so much of their time grappling with this issue.

The term "patient centred counselling" has been used to describe one approach to consultations. ${ }^{24} \mathrm{To}$ date, this has not been developed into a replicable method specifically geared towards negotiating behaviour change in brief consultations, although some encouraging results have emerged from studies of intervention with smokers ${ }^{25}$ and patients with chronic diseases. ${ }^{26}$

In summary, the challenge is to develop methods which ideally are flexible (that is, adaptable to readi- 
ness to change and to more than one behaviour); usable in a brief consultation; teachable; and sufficiently specific to enable proper evaluation to take place. A readily testable hypothesis is that such a method will be more effective than one based on simple advice giving and will enhance both patient satisfaction with the consultation and outcome.

\section{Conclusion}

The pursuit of effective methods for negotiating behaviour change has relevance for many health care consultations, including those entailing the care of patients with chronic conditions affected by behaviours like smoking, drinking, eating, and taking exercise. Consultations to promote health focus almost entirely on negotiating behaviour change. As this activity is being so widely promoted ${ }^{12}$ resources are likely to be wasted unless the methods used and the training in their use are properly evaluated. Simple advice giving may not be sufficiently effective and rewarding for practitioner and patient to warrant widespread use. Against the background of fairly poor success rates the delivery of "lifestyle advice" to as many patients as possible, without evaluating alternatives, is a relatively crude approach. ${ }^{27}{ }^{28}$ Recent developments in research on addiction would seem to enhance our understanding of consultations about behaviour change. Whether more effective methods than giving advice can be developed remains an open question.

1 Department of Health and the Welsh Office. General practice in the National Health Service. A new contract. London: HMSO, 1989.

2 Field J, Henderson J. Better living better life. Henley on Thames: Knowledge House, 1993

3 Tuckett D, Boulton M, Olson C, Williams A. Meetings between experts; an approach to sharing ideas in medical consultations. London: Tavistock Publications, 1985

4 Russell $\mathrm{M}$, Wilson C, Baker C, Taylor C. Effect of general practitioners' advice against smoking. $B M$ J 1979;ii:231-5.

5 Wallace P, Cutler S, Haines A. Randomised controlled trial of general practitioner intervention in patients with excessive alcohol consumption. BMF 1988;297:663-8.

6 Kottke T, Battista RN, DeGriese G, Brekke M. Attributes of successful smoking cessation interventions in medical practice. A meta analysis of 39 controlled trials. $\not A M A$ 1988;259:2882-9.
7 Bien T, Miller W, Tonigan J. Brief interventions for alcohol problems: a review. Addiction 1993;88:315-36.

8 Stott NCH, Pill RM. Making changes: a study of working-class mothers and the changes made in their health-related behaviour over five years. Cardiff: University of Wales College of Medicine, 1990.

9 Orford J. Excessive appetites: a psychological view of addiction. Chichester: Wiley, 1985.

10 Miller WR. Motivational interviewing with problem drinkers. Behavioural Psychotherapy 1983:11:147-72.

11 Miller WR, Rollnick S. Motivational interviewing: preparing people to change addictive behavior. New York: Guilford, 1991

12 Miller WR, Benefield R, Tonigan S. Enhancing motivation for change in problem drinking: a controlled comparison of two therapist styles. f Consult Clin Psychol (in press).

13 Davidson R. Prochaska and DiClemente's model of change: a case study? Br f Addict 1992;87:821-2.

14 Prochaska J, DiClemente C. Criticisms and concerns of the trans theoretical model in the light of recent research. Brf Addict 1992;87:825-6.

15 Prochaska J, DiClemente $\mathrm{C}$. Toward a comprehensive model of change. In: Miller WR, Heather N, eds. Treating addictive behaviors: processes of change. New York: Plenum, 1986.

16 Rollnick S, Heather N, Gold R, Hall W. Development of a short "readiness to change" questionnaire for use in brief, opportunistic interventions among change" questionnaire for use in brief, opportu
excessive drinkers. Br f Addiction 1992;87:743-54.

17 DiClemente C, Prochaska J, Fairhurst S, Velicer W, Velasques M, Rossi J. The process of smoking cessation: an analysis of precontemplation, contemplation, and preparation stages of change. $f$ Consult Clin Psychol 1991;59:295-304.

18 McConnaughy E, Prochaska J, Vellicer W. Stages of change in psychotherapy: measurement and sample profiles. Psychotherapy: Theory, Research and Practice 1983;20:368-75.

19 Health Education Board for Scotland. Drinking reasonably and moderately with self-control (DRAMS). Edinburgh: Health Education Board for Scotland, 1991.

20 Richmond R, Webster I, Elkins L, Mendelsohn C, Rollnick S. Smokescreen for the 1990's. The stop smoking programme for use by general practitioners: manual. Sydney: School of Community Medicine, University of New South Wales, 1991.

21 Royal College of General Practitioners. Alcohol: a balanced view. London: Royal College of General Practitioners 1986. (Report from General Practice 24.)

22 Heather N, Campion P, Neville R, Maccabe D. Evaluation of a controlled drinking minimal intervention for problem drinkers in general practice (DRAMS). f R Coll Gen Pract 1987;37:358-63.

23 Rollnick S, Heather N, Bell A. Negotiating behaviour change in medical settings. The development of brief motivational interviewing. Journal of Mental Health 1992;1:25-39.

24 McWhinney IR. A textbook of family medicine. Oxford: OUP, 1989:87-110.

25 Ockene J, Kristeller J, Goldberg R. Increasing the efficacy of physiciandelivered smoking interventions. A randomized controlled trial. $f \mathrm{Gen}$ Intern Med 1991;6:1-8.

26 Kaplan S, Greenfield S, Ware J. Assessing the effectiveness of patient-centered interactions on the outcome of chronic disease. Med Care 1989;27:110-27.

27 Stott NCH, Pill RM. "Advise yes, dictate no." Patients' views on health promotion in the consultation. Fam Pract 1990;7:125-31.

28 Pill RM, Jones-Elwyn G, Stott NCH. Opportunistic health promotion: quantity or quality. $\mathcal{I} R$ Coll Gen Pract 1989;39:196-200.

(Accepted 5 May 1993)

\section{A PAPER THAT CHANGED OUR PRACTICE}

\section{Functional designation of anaemia}

Most students of medicine would define anaemia merely as a "low" concentration of haemoglobin or packed cell volume. Frank Oski's editorial in 1973 proposed that, at least in premature infants, these traditional measures represent too narrow a view of the function of the blood as an oxygen transporter. ${ }^{1}$ There was, at the time, intense interest in the role of haemoglobin-oxygen affinity in regulating the uptake and release of oxygen by haemoglobin, especially where haemoglobinopathies, fetal haemoglobin, and metabolic disturbances such as diabetic ketoacidosis might alter the course and prognosis of disease by influencing tissue oxygen supply.

Although altered haemoglobin-oxygen dissociation is less academically fashionable now, the notion has persisted of the need to consider how haematological variables other than haemoglobin concentration determine systemic oxygen transport, which is a vital predictor of the outcome in critical illness in patients of all ages. The importance of low blood volume in critical care is becoming clearer. Measurement of blood volume allows more rational blood transfusion treatment, optimising systemic oxygen transport in critical illness but avoiding unnecessary transfusion..$^{23}$ Clinical evidence, as well as physiological theory, shows that the haemoglobin concentration alone is not enough in these assessments; the haemoglobin concentration and blood volume separately determine the adequacy of the blood for systemic oxygen transport and organ perfusion. The limitation of the haemoglobin concentration and packed cell volume is that they both represent merely a ratio of cells to plasma in the blood sample. Because of variations in circulating plasma volume when vascular endothelial integrity falls in critical illness, the usefulness of the haemoglobin concentration as an index of total circulating blood and red cell volumes breaks down. The blood volume is the additional information we need to decide who needs blood transfusion and how much.

We owe the idea of a functional designation of anaemia in no small part to Frank Oski's editorial.-BARBARA HOLLAND is a consutant neonatologist in Glasgow; J JONES is a biochemist in Cardiff; and CHARLES WARDROP is a senior lecturer in haematology in Cardiff.

1 Oski FA. Designation of anemia on a functional basis. $\mathcal{f}$ Pediatr 1973;83: $535-4$

2 Jones JG, Holland BM, Hudson IRB, Wardrop CAJ. Total circulating red cells versus haematocrit as the primary descriptor of oxygen transport by the blood. Br f Haematol 1990;76:288-94.

3 Wardrop CAJ, Holland BM, Jacobs S, Jones JG. Optimization of the blood for oxygen transport and tissue perfusion in critical care. Postgrad Med $\mathcal{F}$ 1992;68(suppl 2):S2-S6.

We are delighted to receive submissions of up to 600 words on $A$ paper (or patient) that changed my practice, $A$ memorable patient, The one message I would like to leave behind, or similar topics. 